\title{
pypet: a python toolkit for simulations and numerical experiments
}

\author{
Robert Meyer ${ }^{1,2^{*}}$, Klaus Obermayer ${ }^{1,2}$ \\ From 24th Annual Computational Neuroscience Meeting: CNS*2015 \\ Prague, Czech Republic. 18-23 July 2015
}

"pypet" (python parameter exploration toolkit [1]) is a new multi-platform python toolkit for management of simulations and storage of numerical data. Exploring or sampling the space of model parameters is one key aspect of simulations and numerical experiments. pypet was especially designed to allow easy and arbitrary sampling of trajectories through a parameter space beyond simple grid searches. Moreover, special focus is put on managing different neuron models in python network simulations like BRIAN [2]. Simulation parameters as well as the obtained results are collected by pypet and stored in the widely used HDF5 file format [3]. This allows fast and convenient loading of data for further analyses.

Furthermore, pypet provides an environment with various features. For example, among these are multiprocessing for fast parallel simulations, dynamic loading of data, integration of Git version control, and supervision of experiments via the electronic lab notebook Sumatra [4]. A rich set of data formats is supported, encompassing native python types, numpy and scipy data, pandas DataFrames [5], and data from BRIAN [2]. Moreover, the toolkit is easily extendible to allow the user to add customized data formats. pypet is a very flexible tool and suited for short python scripts as well as large scale projects. Thus, pypet supports reproducible research in computational neuroscience and other disciplines that involve simulations and numerical experiments.

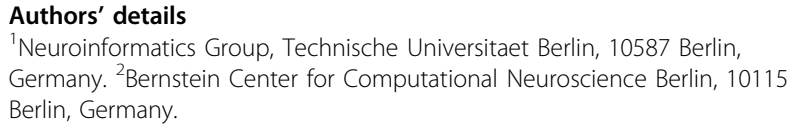

${ }^{1}$ Neuroinformatics Group, Technische Universitaet Berlin, 10587 Berlin, Germany. ${ }^{2}$ Bernstein Center for Computational Neuroscience Berlin, 10115 Berlin, Germany.

Published: 18 December 2015

\footnotetext{
* Correspondence: robert.meyer@ni.tu-berlin.de

${ }^{1}$ Neuroinformatics Group, Technische Universitaet Berlin, 10587 Berlin, Germany

Full list of author information is available at the end of the article
}

\section{References}

1. Meyer R, Obermayer K: pypet [http://pypet.readthedocs.org/], online documentation, 2013-2015.

2. Goodman DF, Brette R: The Brian simulator. Front Neurosci 2009, 3(2):192-197[http://briansimulator.org/].

3. The HDF Group: Hierarchical Data Format, version 5. 1997-2015 [http://www. hdfgroup.org/HDF5/].

4. Davison AP: Automated capture of experiment context for easier reproducibility in computational research. Computing in Science and Engineering 2012, 14(4):48-56 [http://neuralensemble.org/sumatra/].

5. McKinney W: Data Structures for Statistical Computing in Python. Proceedings of the 9th Python in Science Conference 2010, 51-56 [http:// pandas.pydata.org].

doi:10.1186/1471-2202-16-S1-P184

Cite this article as: Meyer and Obermayer: pypet: a python toolkit for simulations and numerical experiments. BMC Neuroscience 2015 16(Suppl 1):P184.

Submit your next manuscript to BioMed Central and take full advantage of:

- Convenient online submission

- Thorough peer review

- No space constraints or color figure charges

- Immediate publication on acceptance

- Inclusion in PubMed, CAS, Scopus and Google Scholar

- Research which is freely available for redistribution

Submit your manuscript at www.biomedcentral.com/submit
C Biomed Central 